\title{
BMP-4 Polymorphisms in the Susceptibility of Cervical Spondylotic Myelopathy and its Outcome after Anterior Cervical Corpectomy and Fusion
}

\author{
Dawei Wanga Wei Liu ${ }^{a}$ Yang Cao Lei Yang Bin Liu Guijun Yao Zhenggang Bi
}

Department of Orthopaedics, The First Affiliated Hospital of Harbin Medical University; No. 23 Post

Street, Nangang District, Harbin 150001, China; ${ }^{a}$ contributed equally to this manuscript

\section{Key Words}

Bone morphogenic proteins-4 - Polymorphisms - Cervical spondylotic myelopathy • Risk • Outcome

\begin{abstract}
Background: To investigate the association between single nucleotide polymorphisms (SNPs) of bone morphogenic proteins-4 (BMP-4) gene and the susceptibility of cervical spondylotic myelopathy (CSM) and its outcome after surgical treatment. Method: A total of 499 patients with CSM and 602 healthy volunteers were recruited. 425 CSM patients received anterior cervical corpectomy and fusion (ACF) and were follow-up until 12 months. The SNPs of BMP4 were determined. Results: For $6007 \mathrm{C}>\mathrm{T}$ polymorphism, the cases had a significant lower prevalence of TT genotype than controls. With the CC genotype as reference, the TT genotype carriages significantly influence the CSM risk. The T allele carriage represented a higher risk for CSM as well. The TT of 6007C $>$ T polymorphisms is also associated with higher chance to gain improvement from ACF surgery. The T allele carriage of 6007C $>$ T had markedly higher chance to have a better post-operative outcome compared with $C$ allele carriage. The genotype and allele distributions of $-5826 \mathrm{G}>\mathrm{A}$ polymorphism did not show positive association with risk and outcome of CSM in this study. Conclusion: BMP-4 genetic polymorphisms may be used as a molecular marker for the CSM susceptibility and its postoperative outcome in those underwent surgical treatment.
\end{abstract}




\section{Introduction}

Cervical spondylotic myelopathy (CSM) is a well-known clinical syndrome of multifactorial origin and is the most common acquired cause of spinal cord disease [1, 2]. A series of environmental factors, such as age, gender, smoking, height, weight were considered to be the risk factors for musculoskeletal degenerative disorders [3, 4]. Additionally, the genetic factors were noted for their important role in the degeneration process of musculoskeletal disorders, including intervertebral degenerative disc disease [5, 6]. However, to date, only few candidate genes predicting the occurrence and development of CSM were documented $[7,8]$.

As a member of bone morphogenic proteins (BMP) superfamily, BMP-4 is a multifunctional growth factor belonging to the TGF- $\beta$ super family which is known to play an important role in regulating osteoblast differentiation and bone formation [9]. The functional role of BMP-4 in bone metabolism is well established, and BMP-4 can induce de novo cartilage and bone formation [10]. Over expression of BMP4 was reportedly associated with progressive heterotopic ossification in humans, fibrodysplasia ossificans progressiva [11]. BMP-4 is increased in concentration during fracture healing [12, 13]. Recombinant human BMP-4 effectively enhances new bone formation and accelerates fusion in the rabbit posterolateral posterior spinal fusion model [14].

Functionally, variants of BMP4 may be synthesized from different single nucleotide polymorphisms (SNPs), resulting in a qualitative or quantitative change in the local production of BMP-4 or in its effectiveness via its cognate receptor [15]. To date, the BMP4 gene SNPs have been reported associated with bone density and posterior longitudinal ligament [16].

Taking into account the role of BMP4 in bone formation and metabolism, we assume that the BMP-4 gene polymorphisms might be related to the risk and severity of CSM. In addition, recently study showed that the gene polymorphisms can predict the outcome after surgical treatment in patients with CSM [8]. We were also interested in investigating whether the SNP of BMP-4 had a prognostic role in CSM after surgical treatment.

\section{Materials and Methods}

\section{Enrolment}

499 consecutive patients being diagnosed as CSM were enrolled in the study from September 2003 to June 2006. The diagnoses were established on the basis of findings from the history, physical examination and confirmed by magnetic resonance imaging (MRI) as previously described [17]. Exclusion criteria included congenital cervical anomalies, trauma, prior cervical surgery, rheumatoid arthritis, infections, tumors, ankylosing spondylitis, ossification of the posterior longitudinal ligament, diffuse idiopathic skeletal hyperostosis, and any other inflammatory disease involving the cervical spine. The control samples consisted of 602 sex and age matched healthy Chinese individuals with negative MRI findings. The clinical characteristics including sex, age, weight, height, body mass index (BMI), daily desk work time, smoking status alcohol use and family history of intervertebral degenerative disc disease were collected. The study protocol was approved by the Ethics Committees Ethical Committee in our hospital. Written informed consent was obtained from all patients before participation in the study. This study was carried out in compliance with the Helsinki Declaration (http://www.wma.net/en/30publications/10policies/b3/index. html).

Follow-Up and Outcome Assessment

Based on the clinical symptoms and signs, the severity of neurological deficits of all these preoperative patients was scored one day before and 12 months after ACF according to the modified Japanese Orthopedic Association (modified JOA) score for CSM [18]. The patients were dichotomized into two groups according to the mJOA scores: improvement group (at least $50 \%$ or higher improvement in mJOA score at the last follow-up compared with pre-operative score) and a non-improvement group (the improvement of mJOA 
score at last follow-up was less than 50\%, equal, or less than pre-operative mJOA score).

\section{Genotyping and SNPs of BMP-4 gene}

Peripheral blood was collected in tubes containing $50 \mathrm{mmol} / \mathrm{L}$ of disodium EDTA. Genomic DNA was isolated with Wizard Genomic DNA Purification Kit (Promega, Madison, WI, USA). The specific product of the BMP-4 gene was amplified by polymerase chain reaction (PCR) with primers 5 '-biotion-TGAAGG CAAGATGTCTGA- CACA-3' (forward) and 5'-CCTTCCTGCATTTCTATC- CTA-3' (reverse) for -5826G>A (rs1957860), and 5'-ATTGCCCAA-CCCTGAGCTATC-3' (forward) and 5'-biotin-TGGGGG-CTTCATAACCTC-3' (reverse) for $6007 \mathrm{C}>\mathrm{T}$ ( $r$ 17563). Reactions were performed in a total volume of $20 \mu \mathrm{l}$ containing $0.2 \mu \mathrm{g}$ of genomic DNA, $3 \mu \mathrm{l}$ of each primer $(1 \mu \mathrm{mol} / \mathrm{L}), 1.2 \mu \mathrm{l} \mathrm{dCTP}$, dTTP, dGTP and dATP mixture (each 2.5 $\mu \mathrm{mol} / \mathrm{L}$ ) (Takara Biotechnology, Dalian, China), $0.15 \mu \mathrm{l} \mathrm{Taq} \mathrm{DNA} \mathrm{polymerase} \mathrm{(Takara} \mathrm{Biotechnology)} \mathrm{and}$ $2 \mu \mathrm{l} 10 \times$ PCR Buffer II (Mg2+ Plus) (Takara Biotechnology) in double distilled water to a final volume of $20 \mu \mathrm{l}$. The thermocycling procedure consisted of initial denaturation at $95^{\circ} \mathrm{C}$ for 3 minutes, 35 cycles of denaturation at $94^{\circ} \mathrm{C}$ for 30 seconds, annealing at $60^{\circ} \mathrm{C}$ for 40 seconds, extension at $72^{\circ} \mathrm{C}$ for 1 minute and a final extension at $72^{\circ} \mathrm{C}$ for 10 minutes. The PCR products were analyzed by electrophoresis on $1 \%$ agarose gel and visualized by ethidium bromide staining. The $-5826 \mathrm{G}>\mathrm{A}$ and $6007 \mathrm{C}>\mathrm{T}$ polymorphisms in BMP-4 gene were detected by direct DNA sequencing for all samples.

\section{BMP-4 expression by western blot}

A total of 93 intervertebral discs were collected during surgery from CSM patients underwent the anterior cervical corpectomy and fusion. Samples were homogenized and lysesed. Extracts were resolved on SDS-polyacrylamide gels followed by transfer to nitrocellulose membranes (BioRad). Proteins were detected by using antibodies to BMP4 (1:1000, Abcam, USA) and GAPDH (1:5000, Santa Cruz). The intensity of the specific bands was quantitated using densitometry analysis (Image Station 4000R Pro; Eastman Kodak, Rochester, NY). The quantitative analyses were performed by using TINA software. The BMP-4 expression levels were quantified by the ratio between the individual density of BMP-4 band minus background and GAPDH minus background.

\section{Statistical Analysis}

Data on quantitative characteristics are expressed as means \pm SD. Data on qualitative characteristics are expressed as percent values or absolute numbers, as indicated. Differences in demographic characteristics and vascular risk factors between patients and controls were compared by using Student's t test or ANOVA for continuous variables and the $\chi 2$ test for all categorical variables. To estimate the deviation of frequency of gene alleles in tested population, we performed the Hardy-Weinberg equilibrium using $\chi 2$ tests. Genotypes and allele frequencies were compared by $\chi 2$ analysis or Fisher's exact test. Multivariate logistic regression analysis was used to determine the influence of BMP-4 polymorphisms on CSM, controlling potential confounding conventional risk factors. A forward stepwise (Likelihood Ratio) procedure was used for multivariable analysis. Data were analyzed with the SPSS 16.0 package (Statistical Package for the Social Sciences, version 16.0, SPSS Inc, Chicago, IL, USA).The results were considered statistically significant at $\mathrm{P}$ $<0.05$ using a 2 -tailed test.

\section{Results}

Table 1 showed the clinical characteristics of cases and controls. There was no significant difference in age, sex and BMI, however, CSM patients had a significantly higher rate of smoker $(\mathrm{P}=0.026)$, heavy alcohol user $(\mathrm{P}=0.001)$ and family history $(\mathrm{P}<0.001)$. In addition, the daily desk work time in CSM patients was significantly longer than controls $(\mathrm{P}<0.001)$. Of all the enrolled CSM patients, 330 (66.1\%) patients had intramedullary signal on T2 MR images. The mean deiseased segments was $3.5 \pm 0.4$. A total of 419 patients received anterior cervical corpectomy and fusion (ACF) and were follow-up.

Table 2 described the genotype distributions and allele frequencies of BMP-4 gene polymorphisms in CSM and control subjects. The genotype frequencies for all polymorphisms 
Table 1. Characteristics of subjects

\begin{tabular}{llll}
\hline Variables & Case $\mathrm{n}=499$ & Control $\mathrm{n}=602$ & $\mathrm{P}$ \\
\hline & & & \\
Age(mean \pm SD,years) & $48.1 \pm 4.3$ & $47.9 \pm 6.7$ & 0.476 \\
Male (n, \%) & $290(58.1 \%)$ & $360(59.7 \%)$ & 0.307 \\
BMI(mean \pm SD, Kg/m2) & $23.4 \pm 2.2$ & $23.3 \pm 1.9$ & 0.652 \\
Smoker (n, \%) & $176(35.2 \%)$ & $178(29.6 \%)$ & 0.026 \\
Heavy alcohol user (n,\%) & $36(8.8 \%)$ & $17(2.8 \%)$ & 0.001 \\
Family history (n, \%) & $94(18.8 \%)$ & $40(6.6 \%)$ & $<0.001$ \\
Desk work time (hour/day) & $8.9 \pm 1.2$ & $5.6 \pm 2.3$ & $<0.001$ \\
Diabetic mellitus (n.\%) & $167(33.5 \%)$ & $182(30.2 \%)$ & 0.139 \\
Intramedullary T2 signal (n,\%) & $330(66.1 \%)$ & - & \\
Diseased segment (mean \pm SD) & $3.5 \pm 0.4$ & - & \\
Underwent ACF & 419 & - & \\
& & & \\
\hline
\end{tabular}

Table 2. The genotype distributions and allele frequencies of BMP-4 gene polymorphisms in CSM and control subjects

\begin{tabular}{|c|c|c|c|c|c|c|c|c|c|c|}
\hline & & CSM & & Control & & $\begin{array}{c}\text { global } \\
\text { P }\end{array}$ & $\begin{array}{c}\text { adjusted } \\
\text { OR }\end{array}$ & \multicolumn{2}{|c|}{$95 \% \mathrm{CI}$} & $\begin{array}{c}\text { adjusted } \\
\text { P }\end{array}$ \\
\hline \multirow[t]{6}{*}{$-5826 G>A$} & & $\mathrm{~N}$ & $\%$ & $\mathrm{~N}$ & $\%$ & & & & & \\
\hline & GG & 128 & $25.65 \%$ & 132 & $21.93 \%$ & 0.214 & 1 & & & \\
\hline & $\mathrm{GA}$ & 236 & $47.29 \%$ & 283 & $47.01 \%$ & & 0.86 & 0.64 & 1.16 & 0.32 \\
\hline & $\mathrm{AA}$ & 135 & $27.05 \%$ & 187 & $31.06 \%$ & & 0.74 & 0.54 & 1.03 & 0.08 \\
\hline & $\mathrm{G}$ & 492 & $49.30 \%$ & 547 & $45.43 \%$ & & 1 & & & \\
\hline & A & 506 & $50.70 \%$ & 657 & $54.57 \%$ & & 0.86 & 0.72 & 1.01 & 0.07 \\
\hline \multirow[t]{5}{*}{$6007 \mathrm{C}>\mathrm{T}$} & $\mathrm{CC}$ & 145 & $29.06 \%$ & 119 & $19.77 \%$ & $<0.001$ & 1 & & & \\
\hline & CT & 243 & $48.70 \%$ & 304 & $50.50 \%$ & & 0.66 & 0.49 & 1.01 & 0.055 \\
\hline & $\mathrm{TT}$ & 111 & $22.24 \%$ & 179 & $29.73 \%$ & & 0.44 & 0.36 & 0.71 & $P<0.001$ \\
\hline & $\mathrm{C}$ & 533 & $53.41 \%$ & 542 & $45.02 \%$ & & 1 & & & \\
\hline & $\mathrm{T}$ & 465 & $46.59 \%$ & 662 & $54.98 \%$ & & 0.51 & 0.61 & 0.85 & $P<0.001$ \\
\hline
\end{tabular}

Fig. 1. The severity of CSM patient stratified by BMP-4 gene polymorphism.

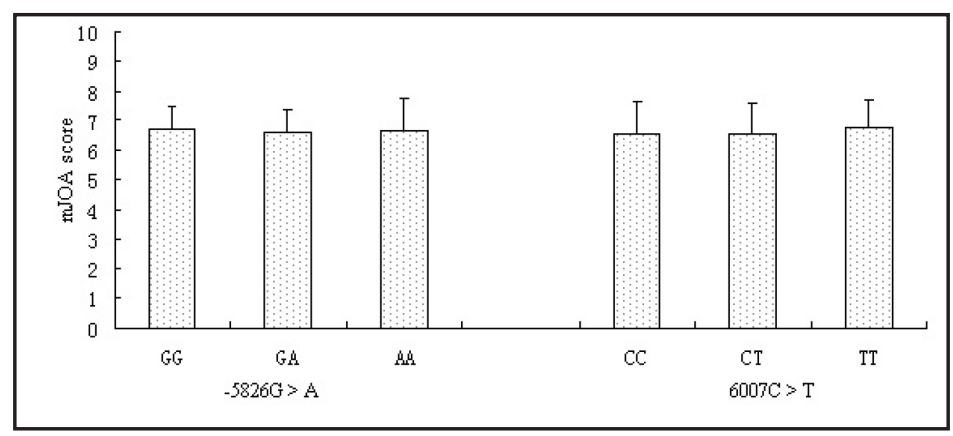

did not differ significantly from those expected under Hardy-Weinberg equilibrium (all $\mathrm{P}>0.05$ ). For rs-5826G $>$ A polymorphism, CSM cases had a lower prevalence of AA genotype than controls $(27.05 \%$ vs. $31.06 \%)$, but did not reach statistical difference $(\mathrm{P}=0.21)$. For $6007 \mathrm{C}>\mathrm{T}$ polymorphism, the cases had a significant lower prevalence of TT genotype than controls $(22.24 \%$ vs. $29.73 \%$, P < 0.001$)$. To determine the independent risk factor for CSM, we preformed multivariate logistic regression analysis with the adjustment with age, sex, BMI, smoking status, family history status and daily desk work time. With the CC genotype as reference, our data showed that the TT genotype carriages significantly influence the CSM risk (adjust $\mathrm{OR}=0.44,95 \% \mathrm{CI}$ : $0.36-0.71$, adjusted $\mathrm{P}<0.001$ ). The $\mathrm{CT}$ genotype carrier also increased the risk of CSM, but did not reach statistical difference $(\mathrm{P}=0.055)$. The $\mathrm{T}$ allele 
Wang et al.: BMP-4 Polymorphisms Predict the Risk and Outcome of CSM

Table 3. The genotype distributions and allele frequencies of BMP-4 gene polymorphisms in post-operative patients with improvement and without improvement

\begin{tabular}{|c|c|c|c|c|c|c|c|c|c|}
\hline & & \multicolumn{2}{|l|}{ Improvement } & \multicolumn{2}{|l|}{$\begin{array}{c}\text { Non- } \\
\text { improvement }\end{array}$} & \multirow[t]{2}{*}{$\begin{array}{c}\text { adjusted } \\
\text { OR }\end{array}$} & \multicolumn{2}{|c|}{$95 \% \mathrm{CI}$} & \multirow[t]{2}{*}{$\begin{array}{c}\text { adjusted } \\
\text { P }\end{array}$} \\
\hline & & $\mathrm{N}$ & $\%$ & $\mathrm{~N}$ & $\%$ & & & & \\
\hline \multirow[t]{5}{*}{$5826 \mathrm{G}>\mathrm{A}$} & GG & 63 & $29.58 \%$ & 49 & $23.79 \%$ & 1.000 & & & \\
\hline & GA & 100 & $46.95 \%$ & 93 & $45.15 \%$ & 0.836 & 0.524 & 1.336 & 0.454 \\
\hline & AA & 50 & $23.47 \%$ & 64 & $31.07 \%$ & 0.608 & 0.359 & 1.028 & 0.062 \\
\hline & G & 226 & $53.05 \%$ & 191 & $46.36 \%$ & 1.000 & & & \\
\hline & A & 200 & $46.95 \%$ & 221 & $53.64 \%$ & 0.765 & 0.583 & 1.003 & 0.053 \\
\hline \multirow[t]{5}{*}{$6007 \mathrm{C}>\mathrm{T}$} & $\mathrm{CC}$ & 52 & $24.41 \%$ & 76 & $36.89 \%$ & 1.000 & & & \\
\hline & $\mathrm{CT}$ & 99 & $46.48 \%$ & 88 & $42.72 \%$ & 1.644 & 1.043 & 2.591 & 0.032 \\
\hline & $\mathrm{TT}$ & 62 & $29.11 \%$ & 42 & $20.39 \%$ & 2.158 & 1.274 & 3.655 & 0.004 \\
\hline & $\mathrm{C}$ & 203 & $47.65 \%$ & 240 & $58.25 \%$ & 1.000 & & & \\
\hline & $\mathrm{T}$ & 223 & $52.35 \%$ & 172 & $41.75 \%$ & 1.533 & 1.167 & 2.014 & 0.002 \\
\hline
\end{tabular}

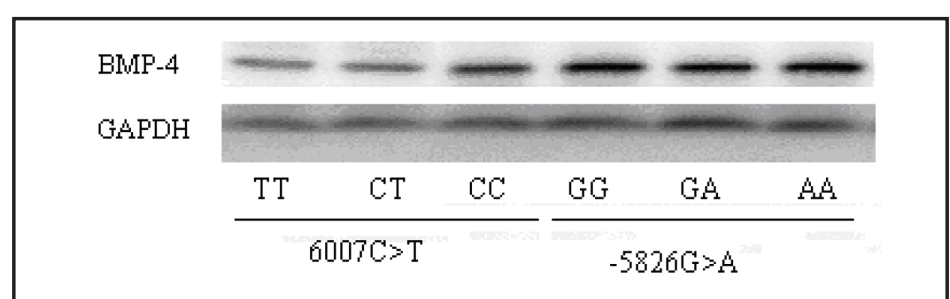

Fig. 2. The typical bands of BMP-4 protein in samples from different genotypes carriers.

carriage represented a lower risk for CSM as well (adjusted OR=0.51, adjusted $\mathrm{P}<0.001$ ). Our data suggest that the $\mathrm{T}$ allele carriage had a protective effect against the occurrence of CSM in studied population.

We evaluated the relation of the BMP-4 SNPs with the severity of 425 patients one day before their surgical CAF treatment by using modified JOA score. We found the pre-operative severity of patients was similar among different genotype carriers (Fig. 1).

We also compared the BMP-4 protein expression in intervertebral disc samples from $93 \mathrm{CSM}$ patients underwent CAF treatment. The genotype distributions of all patients were as following: 6007CC (35), 6007CT (31), 6007TT (27) and -5826GG (24), -5826GA (46) and $-5826 \mathrm{GG}$ (23). Figure 2A shows the typical bands of samples from CSM patients and Figure $2 \mathrm{~B}$ shows the result of quantitative analyses by TINA software. Our results showed that the $6007 \mathrm{C}>\mathrm{T}$ SNPs significantly affected the BMP-4 expression. The BMP-4 protein expression were apparently lower in TT of $6007 \mathrm{C}>\mathrm{T}$ carriers compared to $\mathrm{CC}$ and $\mathrm{CT}$ carriers. In contrast, the $-5826 \mathrm{G}>$ A genotype did not affect the BMP-4 protein expression in different genotype carriers.

All the CSM subjects receiving ACF in this study completed the 12 months follow-up study. No patients died during the peri-operation and follow-up periods. According to the improvement of modified JOA scores, 216 patients were attributed into improvement group and 209 into non-improvement groups. We observed a significant difference in the 6007C $>\mathrm{T}$ polymorphisms between improvement and non-improvement groups. The improvement group had a significantly higher rate of TT genotype and T allele distributions than those without improvement $(29.11 \%$ vs. $20.39 \% \mathrm{P}=0.002$ and $52.35 \%$ vs. $41.75 \%, \mathrm{P}<0.001)$. After adjustment with sex, age, BMI, smoke status, desk work time, family history and surgical treatment, logistic regression analysis showed the TT of $6007 \mathrm{C}>\mathrm{T}$ polymorphisms is associated with higher chance to gain improvement from ACF surgery (adjusted OR=2.158, adjusted $\mathrm{P}=0.004$, compared to $\mathrm{CC}$ genotype, Table 3 ). The CT genotype represented a 
higher chance of improvement as well (adjusted $\mathrm{OR}=1.644$, adjusted $\mathrm{P}=0.032$, compared to $\mathrm{CC}$ genotype, Table 3 ). The $\mathrm{T}$ allele carriage of $6007 \mathrm{C}>\mathrm{T}$ had markedly higher chance to have a better post-operative outcome compared with $\mathrm{C}$ allele carriage (adjusted $\mathrm{OR}=1.533$, adjusted $\mathrm{P}=0.002$, Table 3 ). The genotype and allele distributions of SNP at rs-5826 did not show difference between improvement and non-improvement groups (Table 3).

\section{Discussion}

In the present study, two mostly studied gene polymorphisms of BMP-4, namely, rs$5826 \mathrm{G}>\mathrm{A}$ and $\mathrm{rs} 6007 \mathrm{C}>\mathrm{T}$, were selected to evaluate their association with the susceptibility and the post-operative outcome of CSM. Our data showed a significant difference in the $6007 \mathrm{C}>\mathrm{T}$ genotype distributions as well as the allele frequencies between the CSM cases and controls. Logistic regression showed the $6007 \mathrm{C}>\mathrm{T}$ polymorphisms was significantly associated with the risk of CSM and T allele carriage had a protective effect against the occurrence of CSM. Besides, the polymorphisms at this locus predict the post-operative outcome in those who received ACF. The $6007 \mathrm{C}>\mathrm{T}$ polymorphism significantly affected the BMP-4 expression in the intervertebral disc samples. The BMP-4 protein expressions were significantly lower in TT of $6007 \mathrm{C}>\mathrm{T}$ carriers compared to CC and CT carriers. The TT genotype of $6007 \mathrm{C}>\mathrm{T}$ polymorphisms is associated with higher chance to gain improvement after ACF treatment. The post-operative outcome of CSM patients is quite variable among patients. Clinically, there is still no molecular or biological markers to predict the prognosis of severe CSM patients underwent surgical treatment, our findings suggest that the BMP-4 genetic polymorphisms might be used as a molecular marker for the CSM susceptibility and its postoperative outcome in those subject to ACF treatment. Gene polymorphism detection can be performed very easy with little cost, which makes it very easy for the potential use to predict the post-operative outcome of CSM patients receiving ACF treatment.

The role of BMP-4 expression and bone formation has been well documented. BMP-4 is a potent osteotropic factor promoting bone formation in vivo and in vitro and can strongly induce ectopic ossification $[19,20]$.

Posterior longitudinal ligament (OPLL) is a kind of ectopic bone formation that develops in the spinal ligament. A previous large-scale study screened for candidate genes of OPLL ossification in the spine by cDNA microarray analysis. Among all the candidate genes studied, only BMP-4 reached criteria of suggestive evidence of linkage [21].

The BMP-4 gene is located on chromosome 14q22-23 and the structure of the BMP-4 locus as well as its transcriptional regulation have been determined $[15,22]$. The SNP locus at $-5826 \mathrm{G}>\mathrm{A}$ influence BMP-4 gene transcription. Another SNP of $6007 \mathrm{C}>\mathrm{T}$ present in the coding region of the BMP-4 gene has been reported to affect bone density in postmenopausal women [22]. This polymorphism codes for a nonsynonymous amino acid change with the $\mathrm{T}$ allele coding for valine, while the $\mathrm{C}$ allele codes for alanine [23]. The $6007 \mathrm{C}>\mathrm{T}$ polymorphism was associated with total and intertrochanteric hip Bone mineral density (BMD) and BMD was lower in the subjects homozygous for the $\mathrm{C}$ allele. The authors concluded that a polymorphism found in the BMP-4 gene, affecting amino acid sequence, is associated with hip bone density in postmenopausal women, presumably via regulation of anabolic effects on the skeleton [24].

In Chinese OPLL patients, the frequency of TT genotype and T allele were significantly higher in male OPLL subjects than in male controls. A significant difference was also observed between the $6007 \mathrm{C}>\mathrm{T}$ polymorphism and the number of ossified cervical vertebrae in OPLL patients, while no statistical difference was apparent between the $-5826 \mathrm{G}>\mathrm{A}$ polymorphism and OPLL occurrence [25]. Our data in Chinese CSM patients showed the similar trend. Collectively, these data suggest that the $\mathrm{T}$ allele carriage is closely associated with the OPLL and CSM in Chinese patients. Identification of allele carriage with a simple PCR based technique may be useful to predict the occurrence of certain cervical spine disorders, like CSM or OPLL. 
To date very few study reported the association between related gene polymorphisms and the clinical outcome of CSM after surgical treatment. A study investigated the apolipoprotein E (APOE) gene polymorphism and the outcome after anterior microsurgical decompression in patients with CSM, finding that the APOE gene polymorphism influence the short-term outcome of CSM patients. As far as we know, this is the only study regarding the gene polymorphisms and prognosis of CSM. In this study, we found that $6007 \mathrm{C}>\mathrm{T}$ polymorphism of the BMP-4 gene not only was associated with occurrence of CSM, but also affect the clinical outcome after ACF treatment, implying this $6007 \mathrm{C}>\mathrm{T}$ polymorphism might be a predictor for CSM prognosis. Further study is warranted to explore the mechanism under which the BMP4 gene polymorphisms affect the clinical outcome of CSM.

\section{Conflict of Interest}

None.

\section{References}

1 Tamburrelli F, Di Lazzaro V, Pola E, Genitiempo M, Pilato F, Logroscino CA: Cervical spondylotic myelopathy: proposal of a surveillance algorithm. Eur Rev Med Pharmacol Sci 2008;12:161-165.

2 Tracy JA, Bartleson JD: Cervical spondylotic myelopathy. Neurologist 2010;16:176-187.

3 Oga M, Yuge I, Terada K, Shimizu A, Sugioka Y: Tortuosity of the vertebral artery in patients with cervical spondylotic myelopathy. Risk factor for the vertebral artery injury during anterior cervical decompression. Spine (Phila Pa 1976) 1996;21:1085-1089.

4 Emery SE: Cervical spondylotic myelopathy: diagnosis and treatment. J Am Acad Orthop Surg 2001;9:376388.

-5 Sakai Y, Matsuyama Y, Hasegawa Y, Yoshihara H, Nakamura H, Katayama Y, Imagama S, Ito Z, Ishiguro N, Hamajima N: Association of gene polymorphisms with intervertebral disc degeneration and vertebral osteophyte formation. Spine (Phila Pa 1976) 2007;32:1279-1286.

6 Noponen-Hietala N, Kyllonen E, Mannikko M, Ilkko E, Karppinen J, Ott J, Ala-Kokko L: Sequence variations in the collagen IX and XI genes are associated with degenerative lumbar spinal stenosis. Ann Rheum Dis 2003;62:1208-1214.

7 Wang ZC, Chen XS, Wang da W, Shi JG, Jia LS, Xu GH, Huang JH, Fan L: The genetic association of vitamin D receptor polymorphisms and cervical spondylotic myelopathy in Chinese subjects. Clin Chim Acta 2010;411:794-797.

-8 Setzer M, Vrionis FD, Hermann EJ, Seifert V, Marquardt G: Effect of apolipoprotein E genotype on the outcome after anterior cervical decompression and fusion in patients with cervical spondylotic myelopathy. J Neurosurg Spine 2009;11:659-666.

-9 Hogan BL: Bone morphogenetic proteins: multifunctional regulators of vertebrate development. Genes Dev 1996;10:1580-1594.

10 Maegdefrau U, Arndt S, Kivorski G, Hellerbrand C, Bosserhoff AK: Downregulation of hemojuvelin prevents inhibitory effects of bone morphogenetic proteins on iron metabolism in hepatocellular carcinoma. Lab Invest 2011;91:1615-1623.

11 Shafritz AB, Kaplan FS: Differential expression of bone and cartilage related genes in fibrodysplasia ossificans progressiva, myositis ossificans traumatica, and osteogenic sarcoma. Clin Orthop Relat Res 1998;346:46-52.

12 Nakase T, Nomura S, Yoshikawa H, Hashimoto J, Hirota S, Kitamura Y, Oikawa S, Ono K, Takaoka K: Transient and localized expression of bone morphogenetic protein 4 messenger RNA during fracture healing. J Bone Miner Res 1994;9:651-659.

-13 Bostrom MP, Lane JM, Berberian WS, Missri AA, Tomin E, Weiland A, Doty SB, Glaser D, Rosen VM: Immunolocalization and expression of bone morphogenetic proteins 2 and 4 in fracture healing. J Orthop Res 1995;13:357-367. 
14 Guo X, Lee KM, Law LP, Chow HK, Rosier R, Cheng CY: Recombinant human bone morphogenetic protein-4 (rhBMP-4) enhanced posterior spinal fusion without decortication. J Orthop Res 2002;20:740-746.

- 15 Lin JY, Chen YJ, Huang YL, Tang GP, Zhang L, Deng B, Li M, Ma H, Luan RS: Association of bone morphogenetic protein 4 gene polymorphisms with nonsyndromic cleft lip with or without cleft palate in Chinese children. DNA Cell Biol 2008;27:601-605.

-16 Choi JY, Shin CS, Hong YC, Kang D: Single-nucleotide polymorphisms and haplotypes of bone morphogenetic protein genes and peripheral bone mineral density in young Korean men and women. Calcif Tissue Int 2006;78:203-211.

-17 Mattei TA, Goulart CR, Milano JB, Dutra LP, Fasset DR: Cervical spondylotic myelopathy: pathophysiology, diagnosis, and surgical techniques. ISRN Neurol 2011;2011:463729.

18 Koc RK, Menku A, Akdemir H, Tucer B, Kurtsoy A, Oktem IS: Cervical spondylotic myelopathy and radiculopathy treated by oblique corpectomies without fusion. Neurosurg Rev 2004;27:252-258.

19 Kotajima S, Kishimoto KN, Watanuki M, Hatori M, Kokubun S: Gene expression analysis of ectopic bone formation induced by electroporatic gene transfer of BMP4. Ups J Med Sci 2006;111:231-241.

20 Lin L, Fu X, Zhang X, Chen LX, Zhang JY, Yu CL, Ma KT, Zhou CY: Rat adipose-derived stromal cells expressing BMP4 induce ectopic bone formation in vitro and in vivo. Acta Pharmacol Sin 2006;27:1608-1615.

21 Furushima K, Shimo-Onoda K, Maeda S, Nobukuni T, Ikari K, Koga H, Komiya S, Nakajima T, Harata S, Inoue I: Large-scale screening for candidate genes of ossification of the posterior longitudinal ligament of the spine. J Bone Miner Res 2002;17:128-137.

-22 Ozkan ZS, Deveci D, Onalan Etem E, Yuce H: Lack of effect of bone morphogenetic protein 2 and 4 gene polymorphisms on bone density in postmenopausal Turkish women. Genet Mol Res 2010;9:2311-2316.

23 Antunes Ldos S, Kuchler EC, Tannure PN, Lotsch PF, Costa Mde C, Gouvea CV, Olej B, Granjeiro JM: TGFB3 and BMP4 polymorphism are associated with isolated tooth agenesis. Acta Odontol Scand 2012;70:202206.

-24 Ramesh Babu L, Wilson SG, Dick IM, Islam FM, Devine A, Prince RL: Bone mass effects of a BMP4 gene polymorphism in postmenopausal women. Bone 2005;36:555-561.

25 Meng XL, Wang H, Yang H, Hai Y, Tian BP, Lin X: T allele at site 6007 of bone morphogenetic protein-4 gene increases genetic susceptibility to ossification of the posterior longitudinal ligament in male Chinese Han population. Chin Med J (Engl) 2010;123:2537-2542. 